\title{
Two synchronous malignant tumors of the pancreas: a case report
}

\author{
W. S. L. De Silva ${ }^{1 *}$, A. A. Pathirana ${ }^{2}$, I. Prematilleke ${ }^{3}$, S. A. P. D. Rajapakse ${ }^{3}$, P. S. H. Hettiarachchi ${ }^{4}$, \\ D. S. Manawasinghe ${ }^{1}$ and B. K. Dassanayake ${ }^{1}$
}

\begin{abstract}
Background: Only a limited number of multiple synchronous primary malignancies of the pancreas have been reported in the medical literature. We report a case of two solid malignant tumors of the pancreas diagnosed preoperatively.

Case presentation: We describe a 65-year-old Sri Lankan woman who presented with progressive obstructive jaundice. Initial contrast-enhanced computed tomography imaging detected a malignant tumor at the tail of her pancreas. A second tumor of the pancreatic head was detected with integrated imaging using multidetector computed tomography and multimodal magnetic resonance imaging. She underwent total pancreaticoduodenectomy and splenectomy. Gross examination of the specimen confirmed the presence of two separate tumors. Histology of the ampullary tumor showed pancreatic-type adenocarcinoma and the tumor in the tail of her pancreas showed a colloid-type adenocarcinoma.
\end{abstract}

Conclusion: The possibility of multiple primary malignant solid tumors of different types with malignant potential has to be considered even without background pathology when managing multiple tumors in the pancreas.

Keywords: Synchronous primary pancreatic carcinoma, Total pancreaticoduodenectomy, Ampullary carcinoma

\section{Background}

The finding of synchronous primary tumors involving one organ is rare. Only a few cases of multiple solid primary pancreatic tumors have been reported in the literature $[1,2]$. Most such multiple tumors were found in previously diseased pancreases with chronic pancreatitis [1]. We report our management experience of a preoperatively detected ampullary adenocarcinoma and a mucinous pancreatic adenocarcinoma involving the tail.

\section{Case presentation}

A 65-year-old previously healthy Sri Lankan woman was referred for the management of progressive painless obstructive jaundice of 1-month duration. She had two episodes of cholangitis which had been managed with antibiotics administered intravenously. There was loss of appetite and loss of weight $(12 \mathrm{~kg} /$ month). Her premorbid metabolic equivalent of task

\footnotetext{
*Correspondence: supun85@gmail.com

${ }^{1}$ Post Graduate Institute of Medicine, University of Colombo, Colombo, Sri Lanka

Full list of author information is available at the end of the article
}

(MET) score was $>6$, but was only 3 when she was referred. She was icteric and had mild dependent edema. Her body mass index (BMI) was 17 . There were no palpable abdominal masses.

She had biochemical evidence of obstructive jaundice: total bilirubin $3.4 \mathrm{mg} / \mathrm{dL}$, direct bilirubin $3.0 \mathrm{mg} / \mathrm{dL}$, and alkaline phosphatase (ALP) 624 IU/dL. Contrastenhanced computed tomography (CECT) only identified a $26 \times 37 \mathrm{~mm}$ tumor in the pancreatic tail with a mildly dilated common bile duct (CBD) without an apparent cause for it. Since she was unfit for major surgery an endoscopic retrograde cholangiopancreatography (ERCP) was performed, which demonstrated a stricture with smooth tapering at the distal end of her CBD. The ampulla was prominent but there was no evidence of a mass lesion from which to take a biopsy. Brush cytology from the stricture was negative for malignant cells. A $6 \mathrm{~cm}$ selfexpandable metal stent (SEMS) was inserted. Following the endoscopic intervention, her icterus disappeared and her liver profile improved. In order to find out the cause for 
the distal CBD stricture, a second computed tomography (CT) scan combined with multimodal magnetic resonance imaging (MRI) of her abdomen was performed. This combined CT/MRI of her abdomen detected a second tumor in her pancreas; it was a mass with ill-defined margins of $17 \times 19 \mathrm{~mm}$, which invaded adjacent pancreatic tissue just inferior to the distal end of her CBD. Her superior mesenteric artery or vein was not involved (Fig. 1).

Her American Joint Committee on Cancer (AJCC) stage was $2 \mathrm{~A}$ for both tumors (ampullary tumor $\mathrm{T}_{3}$, $\mathrm{N}_{0}, \mathrm{M}_{0}$ and the tumor of the tail $\left.\mathrm{T}_{2}, \mathrm{~N}_{0}, \mathrm{M}_{0}\right)$. The decision to offer total pancreaticoduodenectomy was taken in a multidisciplinary team (MDT) meeting because of the anatomical location of the two tumors. She was referred to a nutritionist and was optimized with supplementary parenteral nutrition for 3 weeks. She was also vaccinated to prepare her for a possible splenectomy. Her performance status improved within 3 weeks and a total pancreaticoduodenectomy and splenectomy were performed. Her postoperative period was complicated by a lower respiratory tract infection, superficial surgical site infection, and poor glycemic control. She was managed in a surgical ward with the support of endocrinology, microbiology, and nutrition teams and was discharged on the tenth postoperative day. She was discharged on insulin and oral penicillin for prophylaxis. She lost $7 \mathrm{~kg}$ of weight postoperatively but her weight stabilized after the introduction of a special dietary regimen which included six to eight small frequent meals with energy-dense snacks and limitation of food rich in carbohydrates and fat.

A macroscopic examination of the resected specimen revealed two distinct tumors in her pancreas. One was an ampullary tumor measuring $30 \times 30 \times 28 \mathrm{~mm}$. The second tumor was found at the tail and measured
$50 \times 42 \times 40 \mathrm{~mm}$. The distance between the two tumors was $40 \mathrm{~mm}$.

An histologic examination of the ampullary tumor (Fig. 2a) showed a moderately differentiated ampullary adenocarcinoma of pancreaticobiliary type. This tumor had invaded the muscularis propria of her duodenum and the pancreatic parenchyma. Her CBD was not infiltrated by the tumor. Vascular and perineural invasion were not seen. The tumor at the pancreatic tail (Fig. 2b) showed a moderately differentiated non-cystic mucinous (colloid) adenocarcinoma. Perineural invasion was seen, but vascular invasion was not detected. A few areas of chronic pancreatitis were noted in the rest of the pancreas but largely the morphology of the pancreas was normal. Immunohistochemistry findings are shown in Table 1.

She had good quality life after surgery reaching her premorbid MET score of 6 and had a stable weight. However, her serum albumin level was persistently low (median $26 \mathrm{mg} / \mathrm{dL}$ ). She died of severe pneumonia 8 months after surgery.

\section{Discussion}

Synchronous primary tumors of the pancreas are rare and most of them were found in previously diseased pancreases with chronic pancreatitis or associated with premalignant lesions like intraductal papillary mucinous neoplasm (IPMN). An association of IPMN with multifocal ductal adenocarcinoma is well established. Yamaguchi et al. reported that $20 \%$ of cases in a series of 765 patients who underwent surgery for IPMN had pancreatic ductal adenocarcinoma either derived from IPMN or concomitant with IPMN [3]. Solid pseudopapillary neoplasm too is synchronously found with IPMN [4]. However, multifocal involvement in a
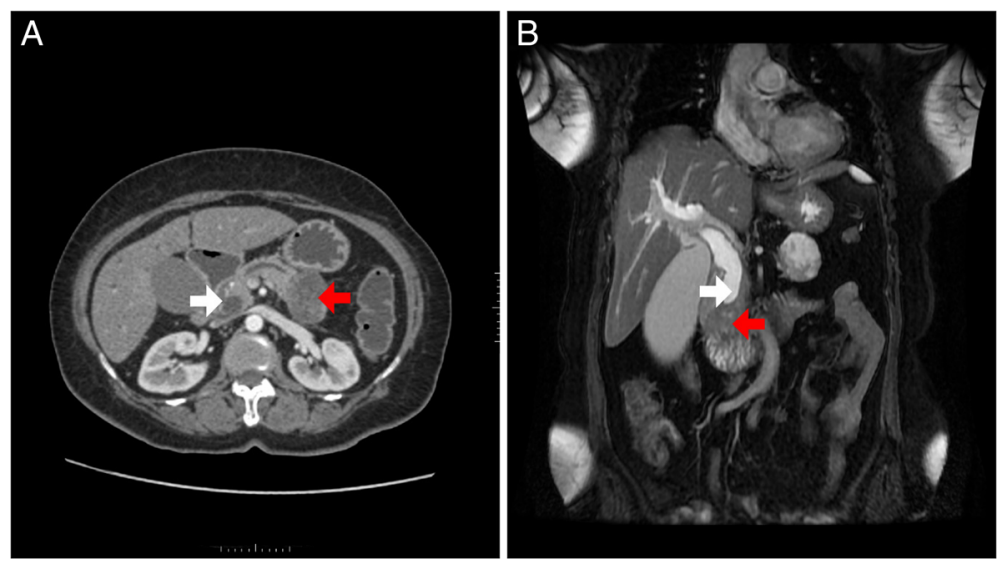

Fig. 1 Imaging of the tumours. a - Axial cut of MDCT showing the two tumors of the pancreas. The ampullary tumour (17×19 mm) with illdefined margins invading adjacent pancreatic tissue (white arrow) and the tumor in the tail of the pancreas ( $28 \times 38 \mathrm{~mm}$ ) with irregular margins (red arrow). $\mathbf{b}$ - A coronal MRI image showing the dilated CBD with smooth tapering stricture at the distal end (white arrow) and the ampullary tumour inferior to the distal end of CBD (red arrow) 


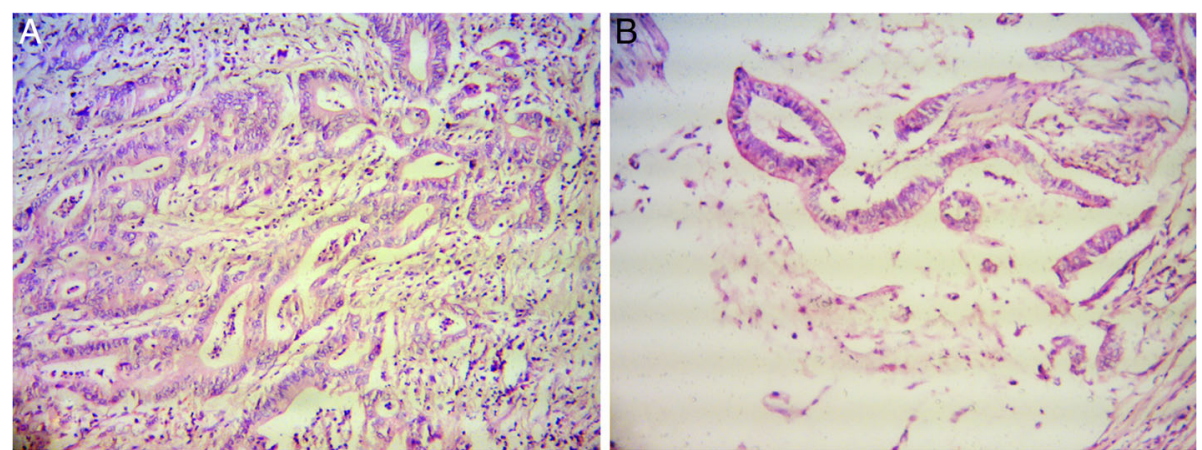

Fig. 2 Histology of two tumors. a Ampullary carcinoma (hematoxylin and eosin $\times 200$ ) is a moderately differentiated adenocarcinoma. $\mathbf{b}$ Hematoxylin and eosin, $\times 200$, shows an adenocarcinoma with tumor cells suspended in pools of extracellular mucin

previously healthy pancreas has not been reported to the best of our knowledge.

A case of two separate malignant tumors of the pancreas was reported by Goong et al. where a tumor in the head and another in the tail of the pancreas were identified preoperatively [2]. Both lesions were finally recognized as ductal adenocarcinomas by endoscopic ultrasound-guided fine needle aspiration biopsy (EUSFNAB), but the histologic separation of the two tumors could not be proven in this case as the patient had refused surgery. Sastry et al. reported a case of three synchronous tumors of the pancreas; an ampullary carcinoma with two other tumors was found incidentally in the head and in the uncinate process, during histologic preparation [1]. In this case, the ampullary tumor was of a poorly differentiated adenosquamous variety whereas the tumor in the uncinate process was a moderately differentiated adenocarcinoma and the tumor in the head of the pancreas was a benign neuroendocrine tumor (NET). Evidence of background chronic pancreatitis was well recognized. On immunohistochemical examination, pancreatic tumors do not have very specific markers. Those we had access to fitted with the morphological diagnosis; ampullary adenocarcinomas of pancreaticobiliary type are usually cytokeratin (CK) $7+1$ CK20- [5] and non-cystic mucinous (colloid) carcinoma

Table 1 Immunohistochemistry of the two tumors (Dako $\left.{ }^{\circledast}\right)$

\begin{tabular}{lllll}
\hline Stain & Cytokeratin 7 & $\begin{array}{l}\text { Cytokeratin } \\
20\end{array}$ & $\begin{array}{l}\text { Carcinoembryonic } \\
\text { antigen }\end{array}$ & $\begin{array}{l}\text { Epithelial } \\
\text { membrane } \\
\text { antigen }\end{array}$ \\
\hline $\begin{array}{l}\text { Tumor } 1 \\
\text { (ampulla) }\end{array}$ & $\begin{array}{l}\text { Strongly } \\
\text { positive }\end{array}$ & Negative & Focally positive & $\begin{array}{l}\text { Strongly } \\
\text { positive }\end{array}$ \\
$\begin{array}{l}\text { Tumor } 2 \\
\text { (tail of } \\
\text { pancreas - } \\
\text { colloid }\end{array}$ & ptrongly & Focally & Strongly positive & $\begin{array}{l}\text { Strongly } \\
\text { positive }\end{array}$ \\
carcinoma) & positive & & \\
\hline
\end{tabular}

CK7+/CK20+ [6]. Carcinoembryonic antigen (CEA) and epithelial membrane antigen (EMA) positivity is reported in both tumors [7].

For accurate diagnosis and staging of pancreatic neoplasms, integrated imaging is recommended. If multidetector computed tomography (MDCT) is the preferred imaging modality, multimodal MRI is recommended for integration in imaging for pancreatic tumors [8]. The cause for obstructive jaundice was not detected in the initial imaging in this case due to the low resolution of the CECT. After ERCP confirmed the presence of a lower CBD stricture, CECT combined with multimodal MRI (integrated imaging) was able to detect the tumor at the head of her pancreas in addition to the previously detected tumor at the tail.

\section{Conclusions}

The possibility of multiple primary malignant solid tumors of different histological types has to be considered when managing multiple tumors in the pancreas. This case demonstrates the importance of utilizing optimum imaging facilities for accurate preoperative diagnosis in order to plan the most appropriate treatment option.

\section{Abbreviations}

AJCC: American Joint Committee on Cancer; ALP: Alkaline phosphatase: BMI: Body mass index; CBD: Common bile duct; CEA: Carcinoembryonic antigen; CECT: Contrast-enhanced computed tomography; CK: Cytokeratin; $C T$ : Computed tomography; EMA: Epithelial membrane antigen; ERCP: Endoscopic retrograde cholangiopancreatography; EUS-

FNAB: Endoscopic ultrasound-guided fine needle aspiration biopsy; IPMN: Intraductal papillary mucinous neoplasm; MDCT: Multidetector computed tomography; MDT: Multidisciplinary team; MET: Metabolic equivalent of task; MRI: Magnetic resonance imaging; NET: Neuroendocrine tumor; SEMS: Self-expandable metal stent

\section{Acknowledgements}

The authors wish to acknowledge the support staff of Asiri Surgical hospital and the Department of Pathology, Faculty of Medical Sciences, University of Sri Jayewardenepura for support in compiling the figures in the article. 


\section{Funding}

No funding was received for this study.

\section{Availability of data and materials} Not applicable.

\section{Authors' contributions}

WSLD followed up the patient, compiled the patient details, and wrote the manuscript. AAP, DSM, BKD, and WSLD were involved in the surgery and the decision making in patient management. PSHH reported on imaging and provided the CT/MRI figures. IP and SAPDR reported on histology and immunohistochemistry and provided images for pathology figures. AAP and IP revised and restructured the manuscript. All authors read and approved the final manuscript.

\section{Competing interests}

The authors declare that they have no competing interests.

\section{Consent for publication}

Written informed consent was obtained from the patient for publication of this case report and any accompanying images. A copy of the written consent is available for review by the Editor-in-Chief of this journal.

\section{Ethics approval and consent to participate}

Ethical approval for the publication of this case report was obtained from the ethics review committee, Faculty of Medical Sciences, University of Sri Jayewardenepura, Gangodawila, Nugegoda, Sri Lanka.

\section{Author details}

'Post Graduate Institute of Medicine, University of Colombo, Colombo, Sri Lanka. ${ }^{2}$ Department of Surgery, Faculty of Medical Sciences, University of Sri Jayewardenepura, Nugegoda, Colombo, Sri Lanka. ${ }^{3}$ Department of Pathology, Faculty of Medical Sciences, University of Sri Jayewardenepura, Nugegoda, Colombo, Sri Lanka. ${ }^{4}$ Department of Radiology, Asiri Surgical Hospital, Colombo, Sri Lanka.

Received: 28 September 2016 Accepted: 21 February 2017 Published online: 28 March 2017

\section{References}

1. Sastry A, Wayne M, Steele J, et al. Three synchronous, sporadic and separate periampullary and pancreatic tumors: more than a coincidence? World J Surg Oncol. 2014;12:382.

2. Goong HJ, Moon JH, Hyun Choi HJ, et al. Synchronous Pancreatic Ductal Adenocarcinomas Diagnosed by Endoscopic Ultrasound-Guided Fine Needle Biopsy. Gut Liver. 2015;9(5):685-8.

3. Koji Y, u S, Hatori T, et al. Pancreatic Ductal Adenocarcinoma Derived From IPMN and Pancreatic Ductal Adenocarcinoma Concomitant with IPMN. Pancreas. 2011;40(4):571-80.

4. Imamura N, Chijiiwa K, Ohuchida J, et al. Synchronous solid pseudopapillary neoplasm and intraductal papillary mucinous neoplasm of the pancreas: report of a case. Surg Today. 2011;41(6):865-71.

5. Zhou H, Schaefer N, Wolff M, Fischer H-P. Carcinoma of the Ampulla of Vater Comparative Histologic/Immunohistochemical Classification and Follow-up. Am J Surg Pathol. 2004;28(7):875-82.

6. Lin F, Wang HL. Chapter 25: Pancreas and ampulla. Tables 25.1 and 25.6. In: Lin F, Prichard J, editors. Handbook of Practical Immunohistochemistry, vol. 2. New York: Springer-Verlag; 2015. p. 482-8. ISBN 978-1-4939-1577-4.

7. Zhu L, Kim K, Domenico DR, et al. Adenocarcinoma of duodenum and ampulla of Vater: clinicopathology study and expression of p53, c-neu, TGF-alpha, CEA, and EMA. J Surg Oncol. 1996:61(2):100-5.

8. Scialpi M, Reginelli A, Gravante S, Falcone G, Baccari P, Manganaro L, Palumbo B, Cappabianca S. Pancreatic tumors imaging: An update. Int J Surg. 2016;28 Suppl 1:S142-55.

\section{Submit your next manuscript to BioMed Central and we will help you at every step:}

- We accept pre-submission inquiries

- Our selector tool helps you to find the most relevant journal

- We provide round the clock customer support

- Convenient online submission

- Thorough peer review

- Inclusion in PubMed and all major indexing services

- Maximum visibility for your research

Submit your manuscript at www.biomedcentral.com/submit
Biomed Central 